\section{Caring for Canada's children}

Life in child welfare care, as you stated in your editorial "Every child deserves a home," is a difficult experience for every child, even when the system works well. In our experience, children and youth yearn for not just a placement but a "home." For many children and youth, this "home" can be found through adoption. For other children and youth, the system can work differently to provide homes when adoption is not the alternative chosen by the young person.

Rules and regulations that impede permanency in placement can be altered. In Ontario, a youth must leave a foster home by 18 years of age because the per diem to foster parents ends. This occurs even when the foster parent and youth wish for another arrangement. In Ontario, while attention is said to be given to Kinship Care placements, little or no support is given to those placements. Youth have said to us, "you can choose your friends and you can choose your family." This support must be given to young people in the care of the child welfare system to choose and build their families.

\section{Irwin Elman}

Provincial advocate for children and youth, Province of Ontario, Toronto

\section{REFERENCE}

1. Eggertson L, MacDonald N, Baldassi CL, et al. Every child deserves a home. CMAJ 2009;181: E265-66.

For the full letter, go to: www.cmaj.ca/cgi/eletters /181/12/E265\#254628

DOI:10.1503/cmaj.110-2012

\section{Why didn't it work?}

Re: "The Enhancing Secondary Prevention in Coronary Artery Disease trial." As a family physician, two possible explanations come to mind for these surprisingly 'negative' results. First, since the patients had elective catheterizations, the primary-care providers may have assumed ongoing follow-up with a cardiologist. Second, with over $80 \%$ on a statin, it is possible that these patients had other comorbidities judged to be of higher priority than reaching a maximal statin dose. I agree with the authors that simple interventions are worth testing and I wonder if the team may have benefited from adding a qualitative component to this intervention. This may have allowed the team to identify barriers to prescribing for coronary artery disease and to potentially adjust the intervention accordingly. The result could have been a perception that the intervention was 'from the ground up,' leading to greater buy-in. Another option may be to conduct interviews with the participating physicians to learn more about why it did not work as expected.

Noah M. Ivers MD

Women's College Hospital, University of Toronto, Toronto, Ont.

\section{REFERENCE}

1. McAlister FA, Fradette M, Majumdar SR, et al. The Enhancing Secondary Prevention in Coronary Artery Disease trial. CMAJ 2009;181:897-904.

For the full letter, go to: www.cmaj.ca/cgi/eletters /181/12/897\#259747

DOI:10.1503/cmaj.110-2020

\section{Where are the drugs from?}

The oxycodone problem is significant, especially in small northern communities, where a little bit of addiction goes a long way in disabling a whole community. Clinicians in our region are aware of the devastation opioid addiction can cause and are careful with prescribing. The authors of "Prescribing of opioid analgesics and related mortality before and after the introduction of long-acting oxycodone" note that many people with fatal overdoses have seen a doctor for a prescription in a preceding time frame. What is not clear is whether that is their main source of narcotics. Do the authors have any information on nonprescribed narcotic abuse/access? Is the problem that individual prescriptions are being misused or the access to illicit bulk narcotic drug trade?

\section{Len Kelly MD}

Northern Ontario School of Medicine

Sioux Lookout, Ont.

\section{REFERENCE}

1. Dhalla IA, Mamdani MM, Sivilotti MLA, et al Prescribing of opioid analgesics and related mortality before and after the introduction of long-acting oxycodone. CMAJ 2009;181:891-6.

For the full letter, go to: www.cmaj.ca/cgi/eletters /181/12/891\#254302

DOI:10.1503/cmaj.110-2017

\section{High cost, dubious benefit}

Re: "Prescribing of opioid analgesics and related mortality before and after the introduction of long-acting oxycodone." In medical school, I was given the textbook Managing Pain: The Canadian Healthcare Professional's Guide. The book recommends prescribing oxycodone over morphine and endorses continuous release opioids because of a "lower abuse potential." The production costs of the manual were paid for by the manufacturer of OxyContin (oxycodone).

Even though opioid misuse is a very complicated issue, some simple changes may be helpful. Eighty milligram oxycodone pills remain on public formulary in Ontario despite the fact that this dose is not supported by current pain management guidelines. ${ }^{2}$ The Committee to Evaluate Drugs recently recommended that $5 \mathrm{mg}$ controlledrelease oxycodone pills not be added to the formulary in Ontario, noting the cost and that "oxycodone has not been demonstrated to be therapeutically superior to morphine or other opioid analgesics." Similar reasoning might lead them to remove oxycodone from the public formulary altogether. The millions of dollars saved could be spent on safer pain management modalities.

The unpleasantness of denying patients opioids sometimes makes it difficult for me to remember that doing so is safe and often appropriate. Indeed, while there is virtually no evidence that 
long-term opioids are helpful in noncancer pain, the study by Dhalla and colleagues shows that writing these prescriptions can be deadly.

Nav Persaud

Family medicine resident

St. Michael's Hospital, Toronto, Ont

\section{REFERENCES}

1. Dhalla IA, Mamdani MM, Sivilotti MLA, et al. Prescribing of opioid analgesics and related mortality before and after the introduction of long-acting oxycodone. CMAJ 2009;181:891-6.

2. Chou R, Fanciullo GJ, Fine PG, et al. American Pain Society-American Academy of Pain Medicine Opioids Guidelines Panel. Clinical guidelines for the use of chronic opioid therapy in chronic noncancer pain. J Pain 2009;10:113-30.

For the full letter, go to: www.cmaj.ca/cgi/eletters /181/12/891\#257431

DOI:10.1503/cmaj.110-2019

\section{Implement research faster}

Stanbrook and Hébert wisely indicated that regulatory health agencies are responsible for acting quickly on new scientific information and making decisions to try to protect the population. ${ }^{1}$ Unfortunately, evidence is lacking for such responsibility. Looking for ways to publish work faster may miss the real challenge. Journals might scrutinize the implementation of published research findings that are both important and time sensitive.

Alain Braillon MD

University Hospital, Amiens, France

\section{REFERENCES}

1. Stanbrook MB, Hébert PC. Disseminate timesensitive research faster. CMAJ 2010;182:9.

For the full letter, go to: www.cmaj.ca/cgi/eletters /cmaj.092077v1\#254133

DOI:10.1503/cmaj.110-2016

\section{Prediction versus prognosis}

Dr. Koch confuses a prediction with a prognostic assessment ${ }^{1}$. A physician can guess (predict) how long a patient will live. Experienced physicians know better than to offer a prediction with any degree of certainty. An accurate assessment of prognosis differs from a prediction in that it requires stating a range of survival based upon relevant data. It would be nice if physicians were clairvoyant, but as Yogi Bera noted: "It's tough to make predictions, especially about the future."

\section{Stephen R. Workman MD \\ Dalhousie University, Halifax, NS}

\section{REFERENCE}

1. Koch T. End of life, year after year after year. CMAJ 2009; 181:868.

For the full letter, go to: www.cmaj.ca/cgi/eletters /181/11/868\#252316

DOI:10.1503/cmaj.110-2013

\section{What did the doctor say?}

Dr. Koch makes assumptions that what the patient tells him is what the doctor said. ${ }^{1}$ As a rule, it is a media type of statement to say that the doctor gave him " $x$ " days, weeks, etc. to live only to show the doctor was wrong. Real doctors rarely make such predictions. Patients remember what they wish to remember or a part of what was said. Patients often tell me what another doctor told them. These statements are often incorrect or taken out of context. Hopefully, Dr. Koch confirmed the six months predictions with the "doctors" who allegedly made the statement.

\section{Stanley A. Hashimoto MD}

University of British Columbia,

Vancouver, BC

\section{REFERENCE}

1. Koch T. End of life, year after year after year. CMAJ 2009;181:868

For the full letter, go to: www.cmaj.ca/cgi/eletters /181/11/868\#247560

DOI:10.1503/cmaj.110-2014

\section{Bridging the gaps}

Re: "Bridging the gaps: getting evidence into practice." Knowledge and science are considered identical by the public. But from a technical terminology standpoint, knowledge refers to "awareness of a fact;" while science refers to "systematically organized body of knowledge." Knowledge management should balance knowledge and science. Patients must be educated with scientific facts in layman's language, and reliable and responsible facts need to be transmitted in the most responsible, educative ways. Prevention rests on such information. $C M A J$, by publishing this article, has opened a way for proper dissemination of knowledge in the field of medicine.

\section{Dhastagir Sultan Sheriff}

Department of Biochemistry, Al Arab

Medical University, Benghazi, Libya

\section{REFERENCE}

1. McGuire W, Fowlie PW. Bridging the gaps: getting evidence into practice. CMAJ 2009; 181:457-8.

For the full letter, go to: www.cmaj.ca/cgi/eletters /181/8/457\#251010

DOI:10.1503/cmaj.110-2015

\section{Doing good in small ways}

Re: "In the street."1 I find Dr. Kulik's effort inspiring for those who are otherwise busy to find time to contribute to a social cause. She has done two good things: one, doing the social service; the other, writing about it so others can know that such problems exist.

\section{Vinod Nikhra MD}

Hindu Rao Hospital, Delhi, India

\section{REFERENCE}

1. Kulik D. In the street. CMAJ 2009; Dec. 16 [Epub ahead of print].

For the full letter, go to: www.cmaj.ca/cgi/eletters /cmaj.109-3136v1\#257130

DOI:10.1503/cmaj.110-2018

\section{Letters to the editor}

In submitting a letter, you automatically consent to have it appear online and/or in print. All letters accepted for print will be edited by $C M A J$ for space and style. Most references and multiple authors' names and full affiliations will appear online only. (The full version of any letter accepted for print will be posted at cmaj.ca.) 